\section{International Scientific Journal Theoretical \& Applied Science}

p-ISSN: 2308-4944 (print) $\quad$ e-ISSN: 2409-0085 (online)

Year: $2016 \quad$ Issue: $11 \quad$ Volume: 43

Published: 02.11.2016 http://T-Science.org
Said Abdullaevich Salekhov

Professor, doctor of medical sciences

Novgorod State University of Yaroslav Mudry, Russia ssalehov@mail.ru

\section{Marya Petrovna Salekhova $\mathrm{PhD}$, cardiologist \\ "Alanda clinic "Kazakhstan salekhova_m@mail.ru}

Nikolay Nestorovich Maksimyuk Professor, doctor of biology sciences Novgorod State University of Yaroslav Mudry, Russia nnm93@ya.ru

\title{
ADAPTATION VALUES OF TYPE 2 DIABETES IN LONG PSYCHOLOGICAL STRESS
}

\begin{abstract}
From the standpoint of the dominant AA Ukhtomskii theory of functional systems PK Anokhin, principles endogenization pathological process, psycho-emotional information-energy theory of obesity and increasing needs of the central nervous system of glucose and kisloroe on the background of the prolonged psychological stress justified the development of insulin resistance as a compensatory-adaptive response to ensure the normal function of the central nervous system on the background of insulin resistance as an alternative energy amino acids are preferably used a substrate, which leads to violation of their scarcity and ornithine cycle protein synthesis in the liver. Reduction of protein synthesis leads to a decrease in blood oncotic pressure, its thickening, disruption of the microcirculation and the transition to the anaerobic catabolism. Violation microcirculation and anaerobic catabolism in the central nervous system leads to energy deficit, offset by hyperglycemia. That is, type 2 diabetes is an adaptive response of the body with long-term psychological stress.

Key words: Type 2 diabetes, psychological stress, adaptation, insulin resistance, hyperglycemia, anaerobic catabolism.

Language: Russian

Citation: Salekhov SA, Salekhova MP, Maksimyuk NN (2016) ADAPTATION VALUES OF TYPE 2 DIABETES IN LONG PSYCHOLOGICAL STRESS. ISJ Theoretical \& Applied Science, 11 (43): 37-40.

Soi: http://s-o-i.org/1.1/TAS-11-43-8 Doi: crossef http://dx.doi.org/10.15863/TAS.2016.11.43.8

\section{АДАПТАЦИОННОЕ ЗНАЧЕНИЕ САХАРНОГО ДИАБЕТА 2 ТИПА ПРИ ДЛИТЕЛЬНОМ ПСИХОЛОГИЧЕСКОМ СТРЕССЕ}

Аннотация: С позиций доминанты А.А. Ухтомского, теории функциональных систем П.К. Анохина, принцииов эндогенизации патологического процесса, психоэмоциональной информачионно-энергетической теории ожирения и увеличения потребности центральной нервной системы в глюкозе и кислорое на фоне длительного психологического стресса обосновано развитие инсулинорезистентности как компенсаторно-приспособительной реакиии для обеспечения нормальной функции центральной нервной системы На фоне инсулинорезистентности в качестве альтернативного энергетического субстрата преимущественно используются аминокислоты, что приводит к их дефициту и нарушению орнитинового цикла синтеза белка в печени. Снижение синтеза белка приводит к уменьшению онкотического давления крови, ее сгущению, нарушению микроциикуляциии и переходу на анаэробный катаболизм. Нарушение микроциркуляции и анаэробный катаболизм в ичентральной нервной системе приводит к энергодефициту, что компенсируется гипергликемией. То есть, сахарный диабет 2 типа является адаптивной реакцией организма при длительном психологическом стрессе.

Ключевые слова: Сахарный диабет 2 типа, психологический стресс, адаптаичия, инсулинорезистентность, гипергликемия, анаэробный катаболизм.

\section{Введение}

В настоящее время частота выявления сахарного диабета 2 типа (СД-2) неуклонно растет $[1 ; 2 ; 3]$ и часто сочетается с такими проявлениями метаболического синдрома (МС)
[4] как алиментарное ожирение (АО) [5], заболеваниями сердечно-сосудистой системы (СС3), артериальной гипертензией (АГ), атеросклерозом [2; 6]. 
Следует отметить, что для СД-2 типа характерно нарушение передачи сигналов инсулина, приводящее к нарушению трофики тканей и перестройке гомеостаза, что в свою очередь сопровождается снижением компенсаторно-приспособительных

возможностей организма, создавая предпосылки для атеросклеротического поражения артерий, развития инфаркта миокарда, инсульта, облитерирующих атеросклероза и эндартериита $[3 ; 7]$.

Особого внимания заслуживает изучение роли инсулинорезистентности (ИР) и гипергликемии (ГГ) в развитии ожирения и, наоборот, значению ожирения как фактора развития СД-2 типа, при котором отмечаются ИР и ГГ $[5 ; 8 ; 9 ; 10]$.

Если рассматривать СД-2 как болезнь образа жизни, необходимо отметить значение психологического стресса (ПС) в его развитии, а саму патологию отнести к психосоматике. При этом психосоматические заболевания, по нашему мнению целесообразно рассматривать не только как следствие дезадаптивных копинг-стратегий, а больше внимания уделить ПС, играющему роль триггера в их развитии, который изменяет метаболизм организма в целом.

С этих позиций развитие СД-2 можно рассматривать как адаптивную реакцию организма в ответ на длительное воздействие ПС.

\section{Материалы и методы:}

В качестве материалов для исследования являлись результаты собственных исследований и анализ научных публикаций, посвященных СД$2 \mathrm{AO}, \mathrm{MC} \mathrm{и} \mathrm{ПС}$

Основой для теоретического обоснования адаптивной роли СД-2 при длительном ПС являлись фундаментальные положения физиологии, психофизиологии, патофизиологии, биохимии и прикладных медицинских специальностей гастроэнтерологии, эндокринологии, лабораторной диагностики.

$$
\text { В качестве методологического }
$$

инструментария использовались:

- принцип доминанты А.А. Ухтомского [11];

- теория функциональных систем П.К. Анохина [12];

$$
\text { - особенности эндогенизации }
$$
патологических процессов;

$$
\text { - материалы }
$$

«Психоэмоциональная

монографии информационноэнергетическая теория ожирения [1].

В соответствии с учением о доминанте А.А. Ухтомского появление приоритетного очага возбуждения в центральной нервной системе, сопровождается перераспределением энергетических и адаптивных ресурсов. При этом все ресурсы направлены на удовлетворение потребностей и запросов доминантного очага возбуждения, а остальные отделы мозга обеспечиваются по остаточному принципу.

Согласно теории функциональных систем П.К. Анохина при воздействии, в том числе психологического фактора, формируется функциональная система, обеспечивающая адекватный ответ-реакцию на предъявляемые требования-запрос к организму, для достижения конечного полезного результата. В случае достижения конечного полезного результата функциональная система прекращает свое существование.

В отличие от этого, когда конечный полезный результат не достигнут, вырабатывается новая стратегия его достижения, используются дополнительные ресурсы и этот цикл может продолжаться многократно. При этом достижение конечного полезного результата и очередность его достижения будет определяться в соответствии с принципом доминанты, приоритетности для организма, поддержания его гомеостаза.

Следует отметить, что при достижении приоритетного конечного полезного результата ресурсы расходуются только на функционирующую функциональную систему, удовлетворение ее запросов.

Основной акцент был сделан на приоритетность обеспечения деятельности центральной нервной системы (ЦНС), которая осуществляет регуляторную функцию всех процессов, протекающих в организме на клеточном, тканевом, органном, системном и организменном уровнях. Так, за счет возбуждения, либо торможения нервных центров происходит анализ афферентной информации, вырабатывается стратегия ответной реакции на нее и передача эфферентного сигнала к органамэффекторам, запуская ряд процессов, способствующих сохранению гомеостаза организма.

Более того, ЦНС обеспечивает координацию и согласованность действия нейрогуморальных регуляторных механизмов. При этом по мере накопления опыта происходит адаптация ЦНС к постоянно меняющимся условиям жизни, совершенствование ее регуляторной функции, что обеспечивает оптимизацию копинг-стратегий при взаимодействии с окружающей средой.

В свою очередь, это обеспечивает устойчивость, целостность, оптимальный уровень жизнедеятельности организма, поддержание его гомеостаза даже при воздействии интенсивных стрессорных нагрузок.

Следует отметить, что активизация той или иной копинг-стратегии зависит от еe

ISPC Education and Innovation, 
приоритетность для поддержания гомеостаза в данный конкретный момент времени и, с учетом этого реализации энергетического обеспечения ответной реакции. При этом отдаленные последствия реализации копинг-стратегии приоритетной для поддержания гомеостаза в ближайшей перспективе, не учитываются, что, в конечном счете, может привести к эндогенизации патологического процесса.

Обоснование адаптивной роли СД-2 при длительном воздействии информационного и эмоционального стрессора

Рассматривая СД-2 как болезнь образа жизни необходимо выделить основные факторы, сопутствующие современному образу жизни, интенсивность которых неуклонно возрастает. Именно информационный и эмоциональный факторы, в совокупности создают психологическую стрессовую нагрузку на ЦНС и отвечают данному критерию.

Под воздействием психологического стресса резко возрастает запрос на энергетическое обеспечение ЦНС, что обеспечивается аэробным катаболизмом глюкозы. Подобный запрос предъявляется организму постоянно, что создает предпосылки для возникновения конкуренции между ЦНС и остальным организмом за обладание глюкозы.

На этом фоне, в соответствии с принципом доминанты А.А. Ухтомского приоритетным является обеспечение глюкозой и кислородом ЦНС. Происходит формирование и активизация функциональной системы для обеспечения конечного полезного результата, а именно, бесперебойное обеспечение ЦНС глюкозой и кислородом.

Учитывая, что запасы углеводов в нервных клетках настолько минимальны, что практически отсутствуют, необходимо обеспечение достаточного уровня глюкозы в крови и увеличением количества крови поступающей к головному мозгу.

Увеличение кровообращения достигается увеличением объемного церебрального кровотока при психологическом стрессе на $15 \%$ при этом потребление глюкозы и кислорода ЦНС возрастает в 2,0-2,5 раза. При этом необходимо не только увеличение кровообращения ЦНС, но и поддержание уровня глюкозы в крови, что достигается включением механизмов, снижающих, либо полностью блокирующих возможность потребления глюкозы клетками организма, в частности развитием резистентности рецепторов клеток к инсулину (ИР).

На фоне ИР, отсутствие возможности использовать глюкозу в качестве энергетического субстрата, компенсируется клетками организма за счет альтернативных энергоносителей - аминокислот (АК) и свободных жирных кислот (СЖК). При этом активизация АК для получения энергии требует меньших энергозатрат, чем активизация СЖК, что приводит к их более интенсивному катаболизму.

Особого внимания заслуживает то, что катаболизм и, вследствие этого, дефицит Lкарнитина снижает транспорт СЖК в митохондрии и липолиз. При этом катаболизм и дефицит глутамина приводит к нарушению трансформации токсичного аммиака в мочевину, то есть имеет место нарушение детоксикационной функции печени. Нарушение синтеза мочевины, которая утилизируется в орнитиновом цикле синтеза белка, сопровождается снижением белоксинтезирующей функции печени.

Снижение синтеза белка приводит к уменьшению онкотического давления крови, нарушению удержания в сосудистом русле воды, что приводит к сгущению крови, нарушениям ее реологических свойств и микроциркуляции.

Нарушение микроциркуляции носит генерализованный характер, в том числе и в ЦНС, что приводит к уменьшению поступления с кровью не только глюкозы, но и кислорода. В результате чего создаются предпосылки для перехода на анаэробный катаболизм со снижением образования энергии в 18 раз, что компенсируется гипергликемией, поскольку даже в анаэробных условиях глюкоза является основным энергоносителем для ЦНС.

\section{Выводы}

Таким образом, вследствие эндогенизации патологического процесса, обусловленных последствиями реакции организма на ПС, СД-2 является средством адаптации для обеспечения энергетического обеспечения ЦНС в условиях анаэробного катаболизма глюкозы.

\section{References:}

1. Salehov SA (2014) Psihoemotsionalnaya informatsionno-energeticheskaya teoriya ozhireniya / S.A. Salehov. - Velikiy Novgorod, 2014. - 180 p.

ISPC Education and Innovation, 


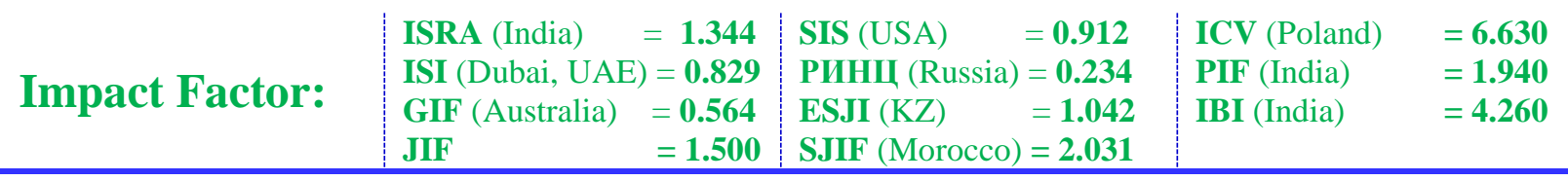

2. Veber VR (2011) Ozhirenie (etiologiya, patogenez, klinicheskie rekomendatsii / V.R. Veber, M.N. Kopina. Velikiy Novgorod, 2011. - 203 p.

3. Kearney MT (2013) Changing the Way We Think About Endothelial Cell Insulin Sensitivity, Nitric Oxide, and the Pathophysiology of Type 2 Diabetes. The FoxO Is Loose / M.T. Kearney //Diabetes, 2013.vol. 62, no. 5. pp. 1386-1388.

4. Reaven GM (1996) Hypertension and Associated Metabolic Abnormalities - The Role of Insulin Resistance and the Sympathoadrenal System / G.M. Reaven, H. Lithell, L. Landsberg // N Engl J Med, 1996. Vol. 334. pp. 374-382.

5. Targher G (2013) Nonalcoholic Fatty Liver Disease: A Novel Cardiometabolic Risk Factor for Type 2 Diabetes and Its Complications / G. Targher, C.D. Byrne // J. Clin. Endocrin. \& Metabol., 2013. Vol. 98, No. 2. pp. 483-495.

6. Bove RM (2013) Metabolic and endocrine correlates of cognitive function in healthy young women / R.M. Bove, D.J. Brick, B.C. Healy, et all. // Obesity, 2013. Vol. 21, Issue 7. pp. 1343-1349.

7. Noyan-Ashraf MH (2013) A Glucagon-Like Peptide-1 Analog Reverses the Molecular
Pathology and Cardiac Dysfunction of a Mouse Model of Obesity / M.H. Noyan-Ashraf, E.A. Shikatani, I. Schuiki et al. // Circulation, 2013. Vol. 127. pp. 74-85.

8. Kahn SE (2006) Mechanisms linking obesity to insulin resistance and type 2 diabetes / S.E. Kahn, R.L. Hull, K.M. Utzschneider. Nature, 2006. 444. pp. 840-846.

9. Hummasti S (2010) Endoplasmic Reticulum Stress and Inflammation in Obesity and Diabetes / S. Hummasti, G.S. Hotamisligil // Circulation Research, 2010. Vol. 107. pp. 579591.

10. Salehov SA (2016) Patogeneticheskie osobennosti razvitiya metabolicheskogo sindroma pri ozhirenii / S.A. Sadehov, M.P. Salehova // Zdorove i obrazovanie v XXI veke. - 2016. - t. 18, \# 1. - pp. 271-276.

11. Uhtomskiy AA (1924) Ob inertsii dominantyi / A.A. Uhtomskiy, M.I. Vinogradov. Sb., posvyasch. 75-letiyu akad. I. P. Pavlova, L., 1924, pp. 47-53.

12. Anohin PK (1970) Teoriya funktsionalnoy sistemyi / P.K. Anohin // Uspehi fiziol. nauk. 1970. T. 1, \# 1. pp. 19-54. 